Editorial / Editorial

\section{The 2011 challenge}

Milton Artur Ruiz ${ }^{1}$

Cármino Antonio de Souza ${ }^{2}$

The Journal of Hematology and Hemotherapy (RBHH) will have a great challenge in 2011; to become a vehicle of international communications. After 11 years of restricted circulation, we are now indexed to the Lilacs, Scopus, Extramed and SciELO Collection databases and are recognized by the national hematology community. The successor, first of the Bulletin and later the Bulletin of the Brazilian Society of Hematology (ISSN 0102 7662), the RBHH has increased the number of communications published per issue and the number of annual issues. Most importantly the national scientific production of this area is in black and white on the journal's pages. Currently, six regular issues, educational supplements and abstracts from congresses are published annually with, for the last three years, the submissions and reviewing system being online. But this is little compared to the dreams of the national hematology community in particular in respect to the ever increasing academic pressure for an internationally recognized vehicle. One of the main reasons for this decision was the new classification of CAPES that downgraded the vast majority of national journals and rewarded those that invested and became global.

Initially, timidly, the RBHH invited foreign hematologists to participate on the Editorial Board and after, with the consolidation of the Brazilian Association of Hematology and Hemotherapy $(\mathrm{ABHH})$ as a single entity in the country, a more aggressive approach was taken, to internationalize the journal. After the new Board of Directors of the ABHH took office, an Advisory Editorial Policy Committee, composed of national hematologists and renowned professors was created which met earlier this year in order to constructively discuss the journal's position and what might or should be done to improve it.

Following these guidelines, the board of the $\mathrm{ABHH}$ agreed with unrestricted support for the journal. So for this first phase, which is still ongoing, an Internal Editorial Committee (IEC) consisting of professionals in communication was created in mid-July this year to discuss and outline measures for the internationalization of the journal.

The influence of the IEC was first felt in issue 5 of 2010, when new, yet subtle, norms were implanted but, at the same time the style of the journal was kept. The IEC found that the layout and the appearance of the journal were of good quality, but concluded that there should be a great investment in the quality of analysis and of content. Thus, we are planning to invite new reviewers to participate and also to renew the editorial board. The IEC also believes it is necessary to publish articles of a high quality, to create new sections in the journal, and also to make public local information peculiar to Brazil, with the aim of being a source of information for both national and foreign journals. The RBHH is one of two Latin American journals in hematology and hemotherapy but it is the only journal south of the equator, which increases our chances of being accepted in international databases. The CIE believe it is essential to invest in electronic media by reorganizing the site and submission link in order to make them more user friendly and accessible in line with SciELO Brazil. All these measures are underway as are the registration to obtain a DOI (Digital Object Identifier) specifically for the journal and the preparation of articles with the tags necessary for the first issue in 2011 to be indexed to PubMed Central. One of the most important decisions of the CIE was to publish the paper copy of the journal in English. The RBHH, since its inception, has stated in its guidelines that it is a bilingual journal. This decision was logical and in keeping with the advice of editors of similar international journals, academics and professors from the area because English is the language of international communications in science; English will provide greater visibility of our scientific production and provides an opportunity for foreign authors to publish. Additionally, it was decided to continue with a parallel publication in Portuguese online for national authors.

Thus, taking all this into account, the $\mathrm{ABHH}$ and the Revista Brasileira de Hematologia e Hemoterapia (Journal of Hematology and Hemotherapy) will need to professionalize all sectors and activities related to production of the journal and, in particular, to count on the support of the scientific community to meet the 2011 challenge.

Submitted: $29 / 12 / 2010$

Accepted: 3/1/2011

${ }^{I}$ Clinical Medicine Department, Hematology and Hemotherapy Section, Medicine School, Universidade de São Paulo - USP, São Paulo (SP), Brazil

${ }^{2}$ President of the Associação Brasileira de Hematologia e Hemoterapia - $A B H H$

Correspondence: Milton Artur Ruiz Rua Catarina Nucci Parise, 760 - Jardim Vivendas 15090-470 - São José do Rio Preto (SP), Brazil

E-mail: brazilbloodjournal@yahoo.com.br 